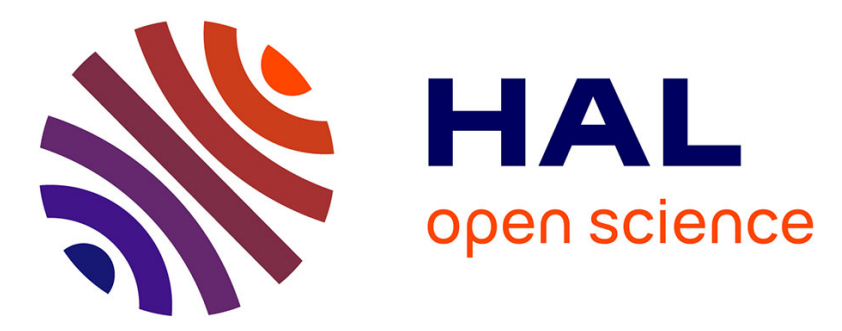

\title{
Interdependent creativity for Learning in a Virtual World
}

Martine Gadille, Maria Impedovo, Joséphine Rémon, Caroline Corvasce

\section{To cite this version:}

Martine Gadille, Maria Impedovo, Joséphine Rémon, Caroline Corvasce. Interdependent creativity for Learning in a Virtual World. Information and Learning sciences, 2021, 10.1108/ILS-02-2020-0038 . hal-03233110

\section{HAL Id: hal-03233110 https://hal.science/hal-03233110}

Submitted on 23 May 2021

HAL is a multi-disciplinary open access archive for the deposit and dissemination of scientific research documents, whether they are published or not. The documents may come from teaching and research institutions in France or abroad, or from public or private research centers.
L'archive ouverte pluridisciplinaire HAL, est destinée au dépôt et à la diffusion de documents scientifiques de niveau recherche, publiés ou non, émanant des établissements d'enseignement et de recherche français ou étrangers, des laboratoires publics ou privés.

\section{다)(1) $(5$}

Distributed under a Creative Commons Attribution - NonCommercial| 4.0 International 


\title{
Interdependent creativity for Learning in a Virtual World
}

\author{
Martine Gadille, Maria Impedovo, Caroline Corvasce, Joséphine Remond. Interdependent \\ creativity for Learning in a Virtual World, Journal of Information and Learning Sciences, \\ Emerald ed., 2021, June, à paraître
}

\begin{abstract}
Recherche financée par la Direction au Numérique Educatif, du ministère de l'éducation français, dans le cadre du dispositif d'Incubateurs Académiques et par l'Institut Français d'Education, dans le cadre du dispositif des Lieux d'éducation associés, ENS Lyon.
\end{abstract}

\section{Abstract}

Category: Research paper

Title: Interdependent creativity for learning in a Virtual World

Keywords: Creativity, sociotechnical network, learning, middle school, Virtual World, pedagogical scenario, professionality

Purpose: The purpose of the paper is to understand how the creativity of pupils and teachers is nurtured through the use of a Virtual World, within a sociotechnical network affecting pupils' learning in a pilot secondary school.

Design/methodology/approach: The analysis is the result of a pluridisciplinary systemic analysis involving didactics, sociology, psychology, and management science on an individual, collective and systemic scale. This Participatory Action Research is based on interviews and systematic observations in class, in-world and in the global ecosystem. Linguistic and multimodal analysis is applied to the data, through teacher monographs that hint at the teachers' activity.

Findings: Pupils' and teachers' creativity appeared to be anchored within four main interdependent nurturing conditions : the personal inclinations and professional interactions in the sociotechnical network sustaining the Virtual World; a creative regulation allowing compromises with the institutional constraints of pedagogical control; avatars and 3D boundary objects that act as a motor of teacherspupils inquiry and creativity; the sociotechnical network that contributes, through the actors' play, to bringing the organisational rules of the school towards an innovation trajectory, that in turns mediates success in the use and the adoption of the new technology.

Research limitations/implications: Although this is a study within a specific school, the findings can be put to use by other pedagogical teams who would wish to integrate a Virtual World to re-engage pupils.

Practical implications: The participatory design processes taking place within a sociotechnical network support teachers in the building of Virtual World scenarios negotiated with researchers and start-up developers.

Social implications: The pedagogical use of a Virtual World opens new learning engagement opportunities for the pupils through enhanced experiential learning and sustains the transformation of teachers' professionality.

Originality/value: Our approach differs from the previous educational VW literature in that we integrate the teachers' creativity and their pedagogical scripts into our study, within a systemic approach, thus requiring a wider theoretical framework, necessary for understanding the building of strategies and knowledge that foster teachers' and pupils' creativity in educational settings using a VW.

\section{Introduction}

The purpose of the present paper is to explore how the creativity of pupils and teachers is nurtured through the use of a Virtual World set within a sociotechnical network. Previously authors have focused on sense-making through embodiment in the VW (Impedovo and Gadille, 2021). Here we analyse the systemic interactions between actors and artefacts within the learning context, focusing on creativity and professionality, thus covering a research gap by bridging the actions of the teachers and technicians with the actions of the pupils. 
We define a Virtual World (VW) as 3D "Shared, simulated spaces which are inhabited and shaped by their inhabitants who are represented as avatars. These avatars mediate our experience of this space as we move, interact with objects and interact with others, with whom we construct a shared understanding of the world at that time" (Girvan, 2018, p 1099).

Some scholars argue that these VW uses in education can create new opportunities for mediating the inquiry and creativity at stake in the engagement of students in learning (Gregory and Wood, 2018). Nevertheless, the effects of using this technology at school can be limited because teachers are limited by a series of constraints that they do not always have the power to change, which explains why they tend to simply transpose their own traditional practice into the VW (Gregory et al., 2016).

If this technology is widely present at home through the use of Massive Multiplayer Online Role Playing Games (MMORPGs) and through WWs such as Second Life, the use of VW in middle schools for educational purposes implies technological adaptations and professional transformations. Indeed the teachers and administrative staff are not necessarily specialized in the development and maintenance of this type of platform, which means they are required to work alongside companies and researchers, at least to ensure the scalability of such innovations (Akrich et al., 2002). We assume that these complex interactions with machines and between humans, within a sociotechnical network participate in the emergence of a hybrid learning space (Gadille and Impedovo, 2019; 2020) and can trigger teachers and pupils' creativity more than the isolated components would do. As recently quoted: "In the parlance of actor-network theory, we focus on networks where machines serve as mediators, by affecting and transforming the interaction that takes place" Tsvetkova et al., 2017, p 3).

Within this complex setting of a VW co-evolving with the sociotechnical network in which it is embedded, we use a pluridisciplinary approach to better apprehend the conditions of the nurturing of teachers' and pupils' creativity and their effects on learning. Our approach involves didactics, sociology, psychology and management science on an individual, collective and systemic scale, viewing learning itself as a multidimensional phenomenon involving acquisition, construction of self and engagement.

The data (interviews, and observations in the classroom, in-world, and within the sociotechnical network) was collected through a Participatory Action Research methodology, and was processed using discourse and multimodal analysis. In order to shed light on the creativity dynamics in the sociotechnical network, we focus on the traces of interactions involving the pupils, the teachers, the researchers and the start-up which supplies the VW. For the present paper we select three teachers and their classgroups, in the shape of monographs, which hint at the systemic quality of the sociotechnical network at stake.

In the first part of the paper, we provide a theoretical frame articulating the concept of creativity as applied to VWs and the concept of sociotechnical network from the point of view of the Actor-Network Theory (ANT) (Latour, 1999a).

In the second part we detail the context of our study and the data collecting protocol, and as well as our analysis methodology. Finally, through teacher monographs, we report our findings, and offer them for discussion.

\section{Creativity as an interdependent dynamic process}

Previous educational VW literature deals with the pupils' learning, and the skills that teachers have to acquire to use the $\mathrm{VW}$ in a relevant way. Our approach differs in that we integrate the teachers' creativity into our study, through their pedagogical scenarios, within a systemic approach, addressing a research gap by allowing a simultaneous apprehension of pupil, teacher and non-human agent interactions. This approach requires a wider theoretical framework, allowing the apprehension of the strategies and knowledge building that foster teachers' and pupils' joint creativity in educational settings using a VW.

\section{Fostering Pupils' creativity through avatars and 3D artefacts for learning}

In this part, we identify, through a revue of literature, how the affordances of VWs sustain creativity and under what conditions, namely: 1) through the use of imagination, 2) through the use of task-based activities, 3) through self-empowerment and identity building,

\section{The affordances of the VW allow the use of imagination}

Creativity as the use of imagination is in keeping with the affordances associated with educational uses of VWs, where pupils communicate through their avatar.

Whether in the context of the use of a digital platform or not, imagination is considered a source of creativity, as confirmed through neuroscience studies: "social-emotional imagination [...] involves or 
is related to meaning-making, narrative construction, pretend play, planning, self-regulation, and moral decision-making. Each of these processes is made possible by imagination. Each also has the potential to support people in exhibiting creativity" (Gotlieb et al., 2019, p 710). It is "internally directed cognition" that "facilitates imagination in that it allows the individual to conduct simulations based on personal experiences using both episodic memories of the past and prospective representations of the future" (Ibid., p 15). It is to be further explored whether the use of the avatar draws on that particular type of introspection.

For these authors, pretend play involves "divergent thinking, associative thinking, insight and problemsolving, narrative development, emotional expression, joy in pretending, and integration of affect" (Ibid., $\mathrm{p}$ 711). These elements seem relevant in the context of a VW where pupils interact through the use of an avatar that they can dress, transform and move about.

Thus, Creativity is present through the exercise of imagination, alteration, and building something new even if on a modest scale. In another analysis of creative episodes in an educational VW, where teenagers debated in the VW through their avatars, around the issue of developing their virtual island, creativity "is strongly associated with emotions, fantasy, individual experience and social experience" (Ferguson, 2011, p 169).

2. The affordances of the VW for student-centred learning and authentic technology use

The question of appealing to imagination is closely linked to that of project-based learning, and experiential learning when it comes to the use of a VW. Indeed, authors argue that "the major characteristic of the learning that occurred in [Second Life] was the application of learning into real-life practice. Learning was enhanced by several of SL's features combined with the project-based instructional design" (Jarmon et al., 2009, p 175).

Another research work, mentions student-centred learning and authentic technology use in relation to the use of avatars. Undertaking a thematic analysis of the teenagers' posts on their discussion forum, she sheds light on an ethos that "aimed at treating staff and students as equals, and that encouraged asking questions, challenging assumptions, trying out ideas and engaging in discussion" (Ferguson, 2011, p 176). It was the combined student-centred learning and authentic technology use that allowed meaningful learning, in accordance to five principles such as "active, authentic, constructive, cooperative and intentional" defined by Jonassen et al. (2003).

For Dawley and Dede (2014) analysed this instructional design allows situated learning that strengthens pupils' engagement. The collective problem-solving process in a VW can be focused, for instance, on the creation of a 3D object, which then becomes the stimulus for creativity.

More recently, Chen and Kent results (2020) focus on "struggling English language learners" and the use of a VW. Their qualitative approach studies perceptions, which are found to be positive, and unveils specific affordances that draw on "task-based principles such as problem-solving, collaboration, learning by doing and authenticity" (Ibid., p 12). They coined that it is indeed the "task-based syllabus" that allowed "to capitalize on the unique features of SL [Second Life] that are conducive to task execution, such as real-world simulation, avatar interaction, multimodality, creativity, flexibility and 3D immersion" (Ibid., p 4).

Thus a problem-solving pedagogy allows the implementation of learning scenarios while using the specific affordances of a VW. Chatsuwan et al. (2020) also combine a VW with problem-based learningoriented scenarios, enhancing lateral thinking. Learners are faced with dilemmas such as building according to the Thai architecture model or building according to modern design principles. They ponder features and utility by using objects from their inventory and constructing buildings according to the issue at stake. Using a VW allows the learners to find an appropriate solution as a group, by searching for information and exchanging their findings.

3. The affordances of the VW for anonymity, self-empowerment, and identity construction The question of engagement in task-based problems in the $\mathrm{VW}$ is related in turn to the question of anonymity, the specific VW affordances are "found to maximize task execution and engagement, thus fostering more authentic and cross-cultural communication, building confidence, boosting motivation empowering learners via avatar anonymity" (Chen and Kent, 2020, p 1).

Authors studying the use of VWs insist on self-empowerment through the manipulation of one's avatar, associated with this form of face and body anonymity, or "behavioural modulation related to the appearance of the avatar, known as Proteus Effect" (Guegan et al., 2016, p 166).

Hammick and Lee (2014), for example, study students' avatarial interactions in focus groups regarding drinking issues. Working around a reluctance to communicate, they conclude that the avatar, by offering a subdued experience of detecting negative cues, leads shy people to feel less fear in communication. This anonymity and confidence building in Educational WWs can offer opportunities for teachers to scaffold the pupils' emerging identity construction, which "requires maintaining a sense of one's core 
self while also conceiving broadly of and skilfully moving between the many aspects of one's identity" and "involves developing and utilizing strategies to refine an aspect of one's identity or to become a hoped-for future self" (Gotlieb et al., 2019, p 713).

These findings cannot be considered separately from the scripts designed and implemented by the teachers in the VW and what happens in the physical classroom. This aspect is all the more crucial in a case such as ours, where the VW is used with middle school pupils around the acquisition of basic skills such as written and oral expression.

\section{Professionality based interactions underpinning the teachers' creativity}

The introduction of a new technology such as a VW in a school generates tensions with the institutional and organizational system and acts as a transformative agent of the teachers' professionality, around the pedagogical scenarios they create.

Evan's definition (2008) of professionality describes "an ideologically-, attitudinally-, intellectually- and epistemologically-based stance on the part of an individual, about the practice of the profession to which s/he belongs, and which influences her/his professional practice". In keeping with this concept, we assume that the teachers' creativity is an essential vector of professionality transformation. As rooted in search and inquiry dynamics, using the VW echoes the desire to break the monotony of their daily work by turning it into play (Amabile, 1996; Mainemelis and Ronson, 2006). This monotony occurs within an institutional frame where the teachers are expected to implement national program contents, to which any transformation is a top-bottom imposed injunction. In this context, teachers seek pedagogical mediations, juggling with strong organizational constraints and scarce resources.

Indeed, on behalf of the teachers, the challenge is to seize the virtual tool's possibilities and integrate them within institutional, professional and personal factors, keeping in mind what is best to address each pupil's needs and re-engage them in the learning process. In their attempt to develop a theoretical framework to analyse how digital technology sustains creative and transformational teaching, others scholars argue that "The idea of 'zone of possibility' suggests that tools don't determine the outcomes, but they do constrain or support certain practices, and this brings teacher creativity to the forefront" (Mishra et al., 2019, p 695).

In addition to the practitioners' skills, another prerequisite for creativity is the cohesiveness of the system, defined as "the resultant of all the forces, acting on the members to remain in the group" (Festinger, 1950, p. 274). Craig and Kelly results (1999) also point out that interdependent creative endeavours are sustained through interpersonal cohesiveness.

\section{Agency skills in a sociotechnical network}

This transformation of the teachers' professionality within a cohesive system around scenarios using 3D artefacts, can be understood within the Actor-Network Theory (ANT) (Latour, 1999a). Even though it is non-human, the VW itself is considered an agent mediating the creativity of enrolled teachers and other network members. In this kind of network, according to the principle of material heterogeneity, conversations, texts, techniques and bodies have an active role to play in social dynamics: "People are networks. Devices are networks. But so, too, are texts" (Callon and Law argue, 1997, p 168). Materials become resources or constraints and "all these elements and materials participate in social ordering (Ibid, p 168). Instead of a rigid opposition between context and technological content, translation chains are at work triggering heterogeneous and interconnected forms of intermediation (texts, rules, devices, etc.) by which the actors modify, evolve and translate their varied and conflicting interests (Latour, 1999b).

If the Actor-Network Theory allows us to apprehend the heterogeneity of agents within a network, sociology of innovation offers conceptual tools for qualifying this network in the context of creativity seen as an interdependent process, such as the concept of sociotechnical network. In the case of educational organizations, "Network leadership, within-school leadership and organizational infrastructures evolve and play an important role in the co-construction of the sociotechnical regimes needed to bring about great and widespread changes in pedagogical practice" (Law and Liang, 2019, p 1340). The introduction and use of a VW in an educational context falls within these regimes: tensions emerge within the network between creative production and norms, beliefs, pedagogical goals, and self-development dynamics (Grassin, 2015). This view is shared by others scholars: "Making new things possible is, hence, not only the effort of a mind that strives to have new ideas, but also the outcome of how we interact with other people and with the artefacts that surround us", Bartels and Bencherki (2013, p 4). 
The framework we have just presented enables us to go beyond the notion of the audience (collaborators, users, perceivers), that does not reflect the agency skills needed for the enrolment and coordination of all actors, who are brought together within the sociotechnical network, in a relationship that is not that of build-in subordination, thus creating space for creativity.

\section{Interdependent creativity within the sociotechnical network}

Within the sociotechnical network as conceptualised above, creativity itself is nurtured in an interdependent way. The actor-network, through its "art of incentive" (Akrich et al., 2002), is assumed to play a crucial role on cohesiveness, within constraints and resources, in the "zone of possibilities". Therefore, the concept of interdependent creativity seems relevant for our context, in which repeated interactions over time between heterogeneous but enrolled partners generate creative dynamics, and trigger new rules within a sociotechnical network. This concept allows us to focus on the collaborative nature of the design dynamics of innovative learning materials, involving collective creativity. Glăveanu (2017) for instance insists on the dialogic dimension of creativity in social interactions between individuals, within concrete and constrained institutions or material contexts. Similarly, Daskolia (2015) and Essonnier (2018) highlight that collective creativity is favoured or hampered by the social agency's nature. The members' expertise, the work organization that bonds them, and their skills and knowledge complement the collective creativity into pedagogical design.

It is this interdependent creativity within a sociotechnical network that we study through the date collected in the context of the e-PIm project.

\section{The e-PIm project: a Participatory Action Research}

\section{The context of the research}

In order to study interdependent creativity within a sociotechnical network in a pedagogical context, we analyse the introduction, use and adaptation of a VW in the light of the creative process in the specific setting of a French secondary school. The "e-PIm" project (Incubator of Immersive Pedagogy for Virtual Reality) involves pupils from 11 to 15 years old in a pilot secondary school. The project is part of the "Digital Plan for Education" launched by the French government in May 2015, involving the distribution of tablets in the school district as part of the "Connected Secondary schools" project. The school started digital experimentation in 2016 , financially supported by a national funding plan.

\section{A Participatory Action Research protocol}

The current project adopts a Participatory Action Research protocol (Mclntyre, 2008), through a pluridisciplinary approach, involving didactics, sociology, psychology and management science. There are three main currents in participatory action research: a pragmatic rational current based on Lewin's work and anchored in organizational development to enhance organization performance and viability, a psychosocial and transformative current from the Tavistock institute that acknowledges the role of the unconscious in social behaviour and collective representation is acknowledged, and an emancipatory critical current strongly inspired by Freire's contributions in the field of pedagogy. The methodology upon which we mainly rely in this research belongs to the last current (Mclntyre, 2008). In this methodology, the researcher's role is to accompany individuals and social groups in questioning the individual and collective identities to which they belong in order to resolve crisis situations. We have integrated to the latter approach contributions from the previous currents in order to articulate social change (professional or community identities with their unconscious aspects) with organizational change (conditions of collaboration and technical conditions implemented). This was necessary from a pragmatic point of view and in keeping with the temporalities of the research. Thus, our Participatory Action Research mobilises both participatory and collaborative processes adopting an emancipatory and critical posture to change practices, through continuous spirals of planning, action, observation, reflection and re-planning (Mclntyre, 2008).

\section{A Participatory Action Research revolving around the pedagogical scenarios}

Our Participatory Action Research is built on the pedagogical scenarios developed by the secondary school teachers in collaboration with a regional start-up company and research partners situated in the 
same regional territory (170 kilometres further south). The pedagogical activities take place in a 3D multi-user virtual environment (MUVE) belonging to the start-up (Immersive CoLab). The project aims at allowing teachers, pupils, parents and the whole educational team to exchange, build knowledge, and undertake projects, manipulations and experiments in various fields.

The Participatory Action Research methodology was adopted over time by all the actors involved, in mutual learning, around the creation of pedagogical scenarios. In the first stages of experimenting with pedagogical scripts, the process took place linearly: the scenario was planned (usually by the teacher together with the technician); implemented in action (in the classroom by pupils); observed (in the data collection phase by the researchers) and then it was the object of reflection (by the pupils) and replanning (by the teachers). With the succession of pedagogical scenarios that have followed one another over time, implementing the pedagogical script has become more circular and participatory: the different phases of the model have been maintained, but each actor has become a more active participant in each stage. For example, the pupils interacted more directly with the ITC company to design virtual spaces, or the company played a more active role in the observation and reflection phase. This process has allowed a proper anchoring of the methodology in the research practice carried out over the years, which has extended over time to the creation of pedagogical scenarios and the institution's entire intervention process.

\section{Research question}

We draw on the theoretical framework described above to explore interdependent creativity in this specific educational setting. In particular, we integrate the pupils' and teachers' creativity within a sociotechnical network perspective and the sociological adoption of this network. Our research question is as follows: how is the pupils' and the teachers' creativity nurtured within a sociotechnical network revolving around an educational VW in a pilot secondary school?

This research question will be tackled through data collected in the context described above.

In our specific context, and based on our review of literature, we assume that:

- the pupils, teachers, and administrative staff, supported by the regionally-based ITC start-up and the researchers, engage in simultaneous translation work and meaning-making technological processes, individually and as a group, finding new opportunities for active learning, each guided by their interest and within professionality dynamics.

- the creative process at the pupils' level cannot be apprehended separately from the complex dynamics at stake between heterogeneous agents involved in the translation activities within the network and in the production of pedagogical scenarios.

\section{Data collection and qualitative data analysis methodology}

The global strategy of data collection started in 2016 and is ongoing, and was undertaken within a pluridisciplinary methodological framework (education, cultural psychology, language sciences, work sociology, innovation management) and according to a longitudinal approach. Our multilevel approach to data collecting has in view an organisational, collective, individual and territorial level of analysis. In this way, we cross our analyses of the appropriation of the 3D space according to different, complementary and pluridisciplinary perspectives. For this paper, we will focus on the teachers' and pupils' creativity as mediated by the VW, within a combined collective and individual perspective. To collect this data, the research protocol consists of systematic observations of the interactions in class, in the VW and the sociotechnical network, from the point of view of the instructional, organisational and environmental aspects. These observations are made through note-taking, photos, verbal exchanges, video capture, e-mails, individual interviews and collecting of the actors' documents. The collected videos, interviews and observations are stored in a closed research cloud, and categorised and shared between the members of the research group.

The data collected are analysed by the researchers involved following a qualitative approach. The research team decides collectively on which segments of the sociotechnical network to focus, and then the researchers distribute the tasks among themselves (in-world capture, on site capture, interviews, etc.). As Bartels and Bencherki argue (2013) "understanding creativity does not require access to individual minds, but is located instead in the observation of the practices through which relationships are established (through series of conjunctions and disjunctions), which constitute the world in which we act and in which individuals are in their turn constituted". Thus, the researchers cross their observations with the video captures, interviews and notes around the evolving pedagogical scripts. The results are submitted to the teachers for review and debate, to limit interpretation bias and increase the teachers' and the researchers' reflectivity. 


\section{Data analysis}

In Table 1 below, we list, among the data that was collected, the elements we use for the present paper.

\begin{tabular}{llllll} 
Teacher & Subject & Modality & Students/Classroom & Scripts & Data \\
\hline Kate & French & $\begin{array}{l}\text { compulsory } \\
\text { curriculum } \\
\text { activity }\end{array}$ & $\begin{array}{l}\text { Full classroom } \\
\text { 32 pupils }\end{array}$ & $\begin{array}{l}\text { Flame of } \\
\text { equality }\end{array}$ & $\begin{array}{l}\text { Interviews, } \\
\text { video,written } \\
\text { feedbacks, } \\
\text { classroom } \\
\text { observation notes }\end{array}$ \\
\hline Charline & English & $\begin{array}{l}\text { Voluntary } \\
\text { attendance } \\
\text { activity }\end{array}$ & 12 pupils & $\begin{array}{l}\text { Babel } \\
\text { Tower }\end{array}$ & $\begin{array}{l}\text { Interviews, video, } \\
\text { written feedbacks, } \\
\text { classroom } \\
\text { observation notes }\end{array}$ \\
\hline Flora & Maths & $\begin{array}{l}\text { Must-do } \\
\text { activity into } \\
\text { the curriculum }\end{array}$ & $\begin{array}{l}\text { Full classroom } \\
\text { 28 pupils }\end{array}$ & Funfair & $\begin{array}{l}\text { Interviews, video, } \\
\text { written feedbacks, } \\
\text { classroom } \\
\text { observation notes }\end{array}$
\end{tabular}

\begin{tabular}{llllll}
\hline Flora Maths & $\begin{array}{l}\text { Homework } \\
\text { activity }\end{array}$ & $\begin{array}{l}6 \\
\text { different class level }\end{array}$ & & $\begin{array}{l}\text { Virtual } \\
\text { space }\end{array}$ & $\begin{array}{l}\text { Interviews, inworld } \\
\text { video, written } \\
\text { feedbacks, } \\
\text { classroom } \\
\text { observation notes }\end{array}$
\end{tabular}

The examples used for this study were tagged on the basis of creative moments. A linguistic (content and discursive) and multimodal analysis was applied to the data. For the three teachers picked out for this study, based on salient elements regarding creativity, the data was encoded manually, according to three interdependent analysis nodes, based on our theoretical framework, to understand how the teachers' and pupils' creativity is nurtured within the sociotechnical network.

\section{Three analysis nodes}

These three nodes are coined, for writing purposes "pupil-based interactions", "professionalitybased interactions", "network-based interactions".

1. pupil-based interactions : interactions with pupils about the content of the scenarios in the design phase and / or its implementation, around:

-the manipulation of the avatar and artefacts in relation to the pupils' creativity, -the invention of new rules of pedagogical control in this transformed learning space, -the curriculum content encountered through inquiry and personal or collaborative creations

2. professionality-based interactions : the professional strategies, beliefs and knowledge of the teacher as related to meaning-making and pedagogical control within the current pedagogical scenario: 
- personal technical and design inclinations

- attitudes towards pedagogical control, digital literacy, research, peers collaboration

-intellectual- and epistemological-based stance, in relation to the practice of the profession

- ideology as embodied institutions through the temporalities of agent/structure play.

3. network-based interactions : interactions with the start-up company, fellow teachers and researchers in the teachers' creation of pedagogical scenario, around:

-technical design constraints (technical constraints in the VW, computers parameters, internet access, programming),

-resources (start-up and middle school material and human supports) and among them artefacts (such as 3D virtual objects and scripts),

-narratives within the pedagogical scenarios supported by the VW.

Through the monographs of three teachers, we articulate our three interdependent analysis nodes as presented above in order to shed light on the creative process within a sociotechnical network, within the frame of the Actor-Network Theory. We first present below the monographs of Kate, Flora and Charline, and subsequently discuss and formalise our research results in the Results and discussion section.

Kate

Kate is the French teacher coordinating an interdisciplinary project using the VW. The data involving her allows us to point out several aspects related to nodes 1) pupil-based interactions, 2) professionalitybased and 3 ) interactions network-based interactions.

From the point of view of professional trajectory (node 2), it is relevant to note that Kate travels frequently and has worked in the past with pupils from different cultures in overseas French territories. From the attitudes viewpoint (also node 2), in general, the teachers taking part in the Participatory Action Research at stake are all volunteers who have a positive inclination and a technology literacy background. Indeed, on the topic of written production, Kate mentions in a debriefing interview (12-122019) the fact that she started testing tools in the context of a workshop organised some time back. During the workshop, she was introduced to digital drafting and valorising of the writing process online. She explains that she went through the stage of understanding that technology could bring an addedvalue, which wasn't at all obvious for her at first. She discovered the implications of "having the means of experimenting with things that work and bring something to the pupils and the teacher".

Secondly, within the scope of nodes 3 ) and 2), the inclination and professional trajectory of the researchers played a role in strengthening the trust within the Action Research process. Kate explains: «it's amazing how a year ago I was anxious at the idea of having the researchers come to my classroom, but not anymore". Inside the research group, no piece of knowledge is considered superior to another in the network, thus initiating a virtuous cycle with effects on teacher identity, including for example the realisation that the research team can pinpoint and valorise a way of functioning. Indeed, during this interview, Kathrine voices her doubt as to whether her way of functioning would be of any interest, since she "tries things without being sure they have any interest, and sees afterwards what is worth keeping". She is then reassured by the researcher as to the value of this process, and concludes that indeed "if you don't take risks, you can't evolve".

Thirdly, still within the scope of nodes 3) and 2), the sociotechnical network dynamics rely on the teachers' social affinities within the school and help strengthen the community using the VW, through its mediations (i.e. artefacts and pedagogical transposition activities). Indeed, this teacher also says: "What I loved was working with a colleague. The fact of having a community of peers is super important", putting in words the fact that it is also because the whole process of introducing the VW technology involves collaboration that there is an added-value.

Within the scope of our analysis node 1) (pupil-based interactions), we analyse tensions that appear between the creation process and pedagogical control. Indeed, Kate mentions an incident whereby a pupil's avatar was banished from the VW - while the pupil continued to go to class - in common agreement with the start-up, because this pupil generated objects outside the assigned space. This codecision is an example of a creative interdependent negotiation of rules within the VW. The pupil acted as a "crazy creator", seizing a possibility of agency in terms of sociomateriality, in relation to an identification process, by invading common workspaces in the VW with his objects, showing that the building process is not necessarily a creative process in itself. Here it is the creative exploration of scholarly limits by the pupil that is noticeable. In her interview, Kathrine then goes on to explain that she 
had to ask the pupils to "tidy up" the VW and that she would have some tidying to do, because "there were cubes everywhere". She even told the pupils that it was like being in her kids' room when they were two years old, thus using a recurrent comparison in teachers' speech (comparing the pupils to younger ones), anchoring her speech in the school form. As the researcher suggests a possible comparison, during the interview, between this process and constructivism in very young children, the teacher mentions with a loaded laugh the fact that the pupil that was recently banished was still acting in this unruly way at a much older age. She does not pick up the researchers' cue on this. She also mentioned this event as an example in front of the pupils during a debriefing. She says to the pupils: "I even told you the tragic story of this ninth grade pupil, the crazy constructor, who got banished", insisting on this last word, and pausing after the adjective "tragic", thus dramatising this event, and making this pupil into an almost mythical figure. Several pupils respond to this by "ahhh, yes!", seeming to have interiorised that such a building spree might not be the right attitude.

Another example within the scope of our analysis node 2) (pupil-based interactions) is a case where, similarly, Kate is not entirely sure how to react and regulate the episode, as she mentions it herself in the interview, when she realises that a pupil in the VW is wearing the same dress she was previously wearing, playing about with the figure of adult authority. This other example of a pupil's creative exploration, as in the building spree example above, links an identification process to sociomateriality on the platform, in an exploration of the limits of received behaviour. This behaviour does not necessarily fall within a predefined category and call for a predefined reaction on behalf of the teacher. The teacher will also have to be creative in her responses to events, as well as in her pedagogical scenarios.

To summarise, these examples show how the creative actions are ensconced within affordances, pedagogical imperatives, beliefs, and explicit or implicit rules. The pupils had identified some possibilities of the tool: in a first example, to create an unlimited number of items; in a second example, to dress the avatars with the same clothes as the teacher. This creativity is the result of a negotiation which takes into account an untold rule in the sociotechnical network: the number of items that can reasonably be built and deposited in the VW; or how acceptable it is to dress like the teacher's avatar.

\section{Flora}

The example of Flora shows the development of her professionality-oriented interactions with the pupils and the artefacts that she used. This process is also done through interactions with her colleagues and past experiences. The technology becomes a vector for the activation and maintaining of the creative interdependence we have defined above.

Indeed, through the interview of Flora (maths), we get access to elements that relate to our analysis node 2) professionality-based interactions in relation to the creative process. When we asked how she adopted the idea of creating a funfair inside the VW, she replies without hesitation that in her past and present experience, games are a means of including and training the disabled pupil she takes care of as a referee teacher. She mentions other factors that combine with this, within the scope of our analysis node 2), namely the fact that she implements this game for children who finish their assignment before the others when the pupils are dispatched in half-groups, thus referring to a professional choice directed at enhancing deep learning. She also states the fact that it was through a friend's friend that she got acquainted with another game that is also part of her practice, thus appealing to a personal level of explanation, within the scope of our analysis node 3) network-based interactions. Creating a funfair in the VW was also a network-based collaborative process (analysis node 3): Flora wanted the pupils to manipulate and move around, within a scenario in the shape of a step by step quest, and the start-up developer suggested the form of a funfair. Flora also makes it clear in the interview that she does not hesitate to present her ideas to the start-up developer in charge. For example, she wished for a virtual tracing compass and discussed it with the developer. Flora sheds light on her attitude, i.e. to suggest an idea, knowing that if her vision is not possible one year, it might be implemented the year after. In the global creative economy, she reasons in the long term as she says herself, extending a "zone of possibilities".

Through these examples, we see how technological development plays a mediating role, through various levels of interaction (teacher-researchers, technology-teachers, teacher-peers, teacherpersonal background and inclinations). We argue that the creative process at the level of the pupils cannot be apprehended separately from these complex dynamics within a close geographical territory. These dynamics take place within organizational space-time constraints that imply an agile negotiation on behalf of the teachers. In view of our analysis nodes 3 ), 1) and 2), the interview of Flora sheds light on an accumulation of constraints (the pupil's constraints, her own professional constraints and institutional constraints) that she has to take into account when using the technology, thus developing a creative response. For instance, in the context of the homework tutoring 
sessions managed in the Virtual World, the teacher is at school while pupils are at home. This session takes place during lunch time so that some pupils have to take the bus to go home, prior to attending the session. The teacher has to handle a new time-space that she was not previously in the habit of dealing with. Furthermore, because of the pupils' enrolment based on their difficulties in mathematics, Flora has to face several combinations of relational and temporal constraints. For example, one pupil arrives late because of the bus, while Flora also has to manage two girls who work together without being friends. On top of that, two other pupils who are friends would like to work together, and one pupil only comes because their parents enrolled them.

Flora has to navigate through the specificities of pupil-related constraints, while dealing with her own. Indeed she herself has work constraints that don't allow her to stay late. She has to teach in that same classroom just after lunch time. In regards to this, the effort and the tiredness are also mentioned in the interview. Besides, she often mentions holidays, planning activities "before or after the holidays", thus pointing at calendar constraints with which she has to deal as well.

One of the responses to these multiple constraints is to draw on a global creative economy, as is hinted to by Flora, when she explains in the interview that she will "reinvest" a scenario that she designed previously, and just change the exercises within this pre-designed frame. She also resorts to gamification, with the help of the start-up company, and splits the homework tutoring sessions into group workshops, although they are traditionally individual work sessions, in order to cater for pupils that belong to many different classes, even if it is an additional constraint for her. To meet external constraints, she innovates in instructional design, voluntarily establishing her own constraints and protocols transforming the core of her professionality (analysis node 2).

As we have shown through this analysis around our three nodes, if inquiry is indeed part of the interdependent creative process, it nonetheless shapes itself around institutional, communal and personal constraints, beliefs and perpetuated myths. Thus the aim does not appear as being creation at any cost, but creation within certain boundaries, and with precise goals in mind. It does not mean that these goals and constraints kill creativity but that it is within this specific context that the pupils and protagonists seize interdependent creativity dynamics. It is at the very junction of these dynamics that the teachers' choices unfold. Such is the example of the collaborative building of a Babel Tower that we present in the next section through Charline's monograph.

\section{Charline}

This part focuses on inquiry activities from the point of view of interaction with the artefacts and scripts, enlightening interdependent creativity further. Indeed, in this part we analyse the pupils' inquiry activities and creativity in the $\mathrm{WW}$, in the context of English language learning with Charline, within a scenario entitled "Babel" that was built along the way while taking on board 3D virtual objects. Focusing first on our analysis node 1) pupil-based interactions (artefacts), and 3) networked-based interactions (scripts), we detail Charline's scenario and then tackle the issues at stake as regards creativity as an interdependent process. It is noticeable that Charline is fond of the principle of citizenship. She is a Deputy Mayor, delegate for school affairs and culture in her hometown.

In the context of one of the many school lunch-hour clubs, Charline, who is the English teacher, suggested organising an English club in the virtual school. One of the activities she suggested was the construction of a Babel tower (Figure 1) by the pupils. 


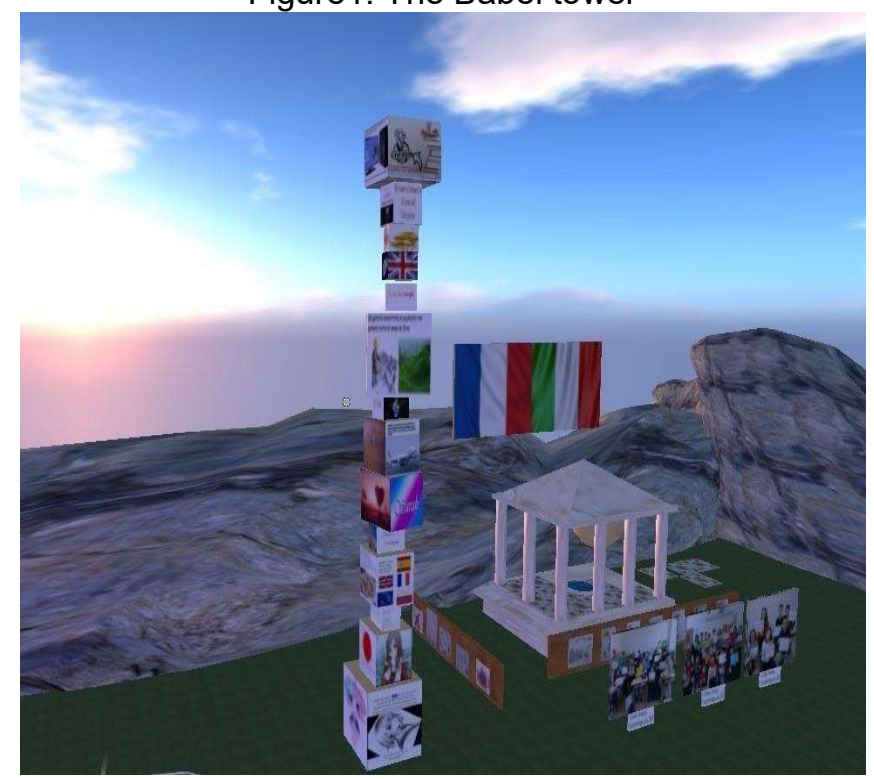

She first told the pupils the story of the Babel tower (from the bible, the construction of a building meant to reach up to heaven caused god's wrath, who then punished the people by creating a diversity of languages, thus making cross-understanding impossible), then showed a tower built in 2001 from radio transmitters at the Museum of Modern Art in London. Taking inspiration from this tower of sorts, the teacher asked each pupil to create a cube onto which information would be pasted. The final Babel tower, named Babel 2020, was made from the piling up of all these cubes.

The process was the following: first, the pupils had to collectively think about what they wanted to include on each side of a cube. Each side corresponded to a research theme that was negotiated between teacher and pupils (analysis node 1). They narrowed down six topics: individual presentation (first name and short presentation text), hobby, favourite town, favourite country, dreams. The last theme, "dream job", was added by the teacher. She says: "I told them: you're going to personalise a cube, what would you like to put on it? They said: we would like to speak about our dreams, we would like to speak about a town we've been to and I summed up their wishes. I added the dream job because, in terms of citizenship, it's good to be able to project oneself into the future", thus showing she does not lose track of her pedagogical objectives, and of wider social issues in terms of citizenship (analysis node 2). The pupils chose four themes among the initial six, and started looking for pictures illustrating these themes, as well as looking for inspiration from the graphic design of internet pages, for the writing of their name on a face of the cubes. The teacher let them choose which language they would like to use to introduce themselves. In the interview, she said it was to disinhibit their creative process. Some introduced themselves in English, others in Italian or Spanish, and some wrote multilingual presentations.

After having negotiated precisely with their teacher in which place to build the tower in the virtual space dedicated to language learning, the pupils stacked together the different cubes one on top of the other (analysis node 1). For this session, the maths teacher was also there to help set up the cubes according to $x, y$ and $z$ coordinates, interacting with the pupils and Charline (analysis node 3 ) while implementing the pedagogical scenario. Finally, each pupil recorded the sentence introducing themselves, to be heard whenever a user clicks on the cube. To record the pupils' voices, Charline tried first to do it herself but the quality of the files was not sufficient (noise). So she asked the start-up developer, present on that day with the researchers, to help her. He walked into the physical classroom and recorded the pupils on his computer, then sent them to Charline, thus keeping her mobilised in the creation process (analysis node 3).

Through a unique negotiation between the technical options and her pedagogical knowledge Charline created a task that could only be completed through the assembly of individual building bricks, thus transferring agency to each pupil, whose responsibility it was to complete their part. Even though one cube was enough to answer the given task, some pupils who had finished their work ahead of the others 
created several cubes to build their miniature version of the Babel tower, thus demonstrating situated learning engagement (Dawley and Dede, 2014), and scenario co-creation, to a certain extent, through the choice of themes and languages. All the pupils were active and completed the scenario, in some cases with a delay resulting from informal exploration in the VW. Indeed, observations in class, at home and in-world, show some pupils explore outside what is planned by the teachers' scenario. For example, a pupil receiving tutoring for critical attentional difficulties, spent 30 minutes on his lunch hour at the English club searching the interface to find how to create an unsafe 3D shape, until he succeeded (Figure 2).

Figure 2: Creating an unsafe 3D volume through the pupil's initiative and search

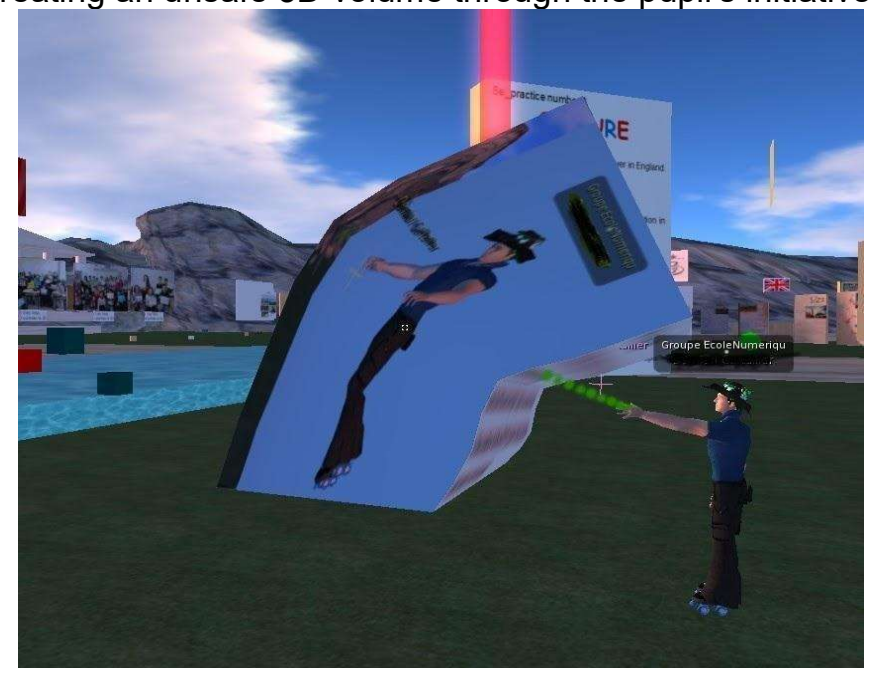

Furthermore, the research team found out that the pupils showed the results to their family or their friends, in keeping with the general observation that building artefacts in the VW in collaboration with others, seems to contribute to creating experiential and situated learning strengthening both the sense of pride and of belonging at school.

In keeping with our analysis nodes 1), 2) and 3), this scenario, while engaging the pupils' creativity, draws on knowledge and collective creation from previous scenarios. Indeed the critical elements of the Babel scenario are the result of a collective, cumulative creative process, reaching outside the school, through translation activities within the sociotechnical network, drawing on interactions that took place between the teacher, researchers, the pupils and the developer, within a previous scenario, around the creation and animation of artefacts.

\section{Results and Discussion}

The analysis of creativity-related episodes within the sociotechnical network around our three interdependent analysis nodes results in the shaping of four nurturing conditions that enable us to argue in favour of interdependent creativity in a sociotechnical network. Table 2 below shows how these conditions appeared through the coding of creativity-related episodes in the three monographs. It should be noted that it is node 1 (pupil-based interactions) that appeared to have to be divided into two emerging and interacting conditions:

- affordances within the 3D VW create opportunities and constrain action, because of technical rules and the new associated needs for regulation;

- $\quad$ scenarios evolve due to the creativity of teachers and pupils, and their mastery of new technical knowledge. 


\begin{tabular}{|c|c|c|c|}
\hline Kate & Flora & Charline & $\begin{array}{l}\text { Interdependent } \\
\text { creativity nurturing } \\
\text { conditions within the } \\
\text { sociotechnical network }\end{array}$ \\
\hline $\begin{array}{l}\text { Travels, personal } \\
\text { inclination for } \\
\text { technology }\end{array}$ & $\begin{array}{l}\text { Attitude towards } \\
\text { games, skills with } \\
\text { disabled children }\end{array}$ & $\begin{array}{l}\text { Attitude towards } \\
\text { citizenship (deputy } \\
\text { mayor) }\end{array}$ & $\begin{array}{l}\text { 1. Personal and } \\
\text { professional } \\
\text { background and } \\
\text { inclinations }\end{array}$ \\
\hline $\begin{array}{l}\text { Artefact manipulation: } \\
\text { regulation of building } \\
\text { and dressing }\end{array}$ & $\begin{array}{l}\text { Funfair inside the } \\
\text { VW with chat, } \\
\text { embodied use of } \\
\text { virtual protractor }\end{array}$ & $\begin{array}{l}\text { English club in the virtual } \\
\text { school, Babel tower }\end{array}$ & $\begin{array}{l}\text { 2. Affordances within } \\
\text { the 3D Virtual World }\end{array}$ \\
\hline $\begin{array}{l}\text { Link between an } \\
\text { identification and } \\
\text { socio-materiality } \\
\text { (same dress as the } \\
\text { teacher) }\end{array}$ & $\begin{array}{l}\text { Proposed as } \\
\text { enhancing deep } \\
\text { learning for faster- } \\
\text { working pupils; } \\
\text { Gamification within } \\
\text { a creative economy }\end{array}$ & $\begin{array}{l}\text { Narrative modality used } \\
\text { through the story of } \\
\text { Babel in view of creating } \\
\text { a cube onto which } \\
\text { information will be } \\
\text { pasted. }\end{array}$ & $\begin{array}{l}\text { 3. Scenarios as agents, } \\
\text { involving avatars and } \\
\text { 3D artefact }\end{array}$ \\
\hline $\begin{array}{l}\text { Community of peers, } \\
\text { strengthened } \\
\text { professional identity }\end{array}$ & $\begin{array}{l}\text { Homework tutoring } \\
\text { session to scaffold } \\
\text { engagement }\end{array}$ & $\begin{array}{l}\text { Negotiation, extension to } \\
\text { family, informal } \\
\text { exploration, extra } \\
\text { tutoring }\end{array}$ & $\begin{array}{l}\text { 4. Sociotechnical } \\
\text { network regulation }\end{array}$ \\
\hline
\end{tabular}

Table 2: Action based identification of interdependent creativity nurturing conditions

These four main nurturing conditions, i.e. the conditions necessary for interdependent creativity to take place within the sociotechnical network, can be summarized as following:-

1. Personal and professional background and inclinations, underpin professional interactions within the sociotechnical network around the Virtual World, and scaffold teachers' creativity;

2. Affordances within the 3D Virtual World allow for new kinds of transgression within experiential learning, that call for a creative regulation alongside compromises with the institutional constraints of pedagogical control;

3. Scenarios as agents, involving avatars and 3D artefact, appear to act as an enhancer of teacher-pupil inquiry fostering at the same time teachers' and pupils' technical knowledge ;

4. Sociotechnical network regulation, through the actors' creativity and play, contributes to bringing the school's organizational rules towards an innovation trajectory, which mediates success in using and adopting the new technology.

The interdependent nature of creativity in our specific context, as it appears through our analysis, involves teachers, a start-up company, pupils and researchers, and further hints at strategies that can be implemented to foster these processes in educational settings (Bartels and Bencherki, 2013; Grassin, 2015). Indeed, we argue that pupils' inquiry and creativity result from a cumulative and complex idea 
generation process and translation activities producing heterogeneous things (Latour, 1999b), whereas existing literature on technological innovation in education has not deeply articulated the processual approach of creativity with the concept of sociotechnical innovation network.

In line with our research question, which was how the pupils' and the teachers' creativity is nurtured within a sociotechnical network introducing a VW, our analysis helps to show how transformative learning is a mutual process, where the dimensions at stake are interconnected. The human and nonhuman agents support the sociotechnical network to perform mutual learning.

Our results point at some nurturing conditions of interdependent creativity, which draws on the continuous exchange process between human and non-human actors, and the heterogeneity of actors, methods and procedures in place. Within this heterogeneity, the interactions are nurtured by each partner's inclinations and background, by their professional trajectory and identity and by the pedagogical control of the 3D technology implemented in the school. Indeed, the global process of translation while innovating technologically for instructional design can be broken into elements such as tensions between creation sprees in the pupils and pedagogical goals, or the valuing by the teacher of the practice of transversal skills, with the overall aim of strengthening experiential learning with the authenticity of the real world (Jarmon et al.,2009) and allowing situated learning among peers through VW multimodal communication (Dawley and Dede, 2014).

The teacher's professional trajectory is lodged into personal background and inclinations, interactions with the peers, the research team, and the technical team. The start-up developers are under technical, corporate and institutional constraints, which also influence creativity in the teachers' actions and their pedagogical control in the VW. The pupils' suggestions are tributary of these global dynamics, which they also, at the same time, put into motion. Indeed, the pupils are active protagonists who are fully present in the process. They engage in formal academic activities in the classroom and informal activities at home and in-world or class. The pupils' creativity is present both in the learning activity and the active exploration of the virtual resources and adaptive responses. They are proactive in suggesting scenarios to the teacher, who then negotiates their feasibility.

The teacher's scenario, in this way, is embedded in a space of creativity spreading to the whole school and the regional territory, and is the result of the tensions within the translation activities associated with disorder and order in rule setting (Mishra et al., 2019). The Virtual World as a non-human actor thus takes the teachers a step further in the building of their professionality. Furthermore, in the various research phases, the actors, scenarios, and processes have cyclically transformed, in an inclusive and progressively more complex Participatory Action Process.

\section{Conclusion}

We have explored above the implications of a sociotechnical network for the actors' creativity in a secondary school, in relation to the teachers' professionality and the learning dynamics. In the specific sociotechnical apprehension of creativity presented in this paper, we have shed light on how experiential learning is acted within a multilevel approach, implying organizational, collective and individual transformations. For this process to occur, all the stakeholders need to be involved in content-related and collaborative actions: only when the new, initially self-contained activity is put into practice, generating a rich ecosystem, can the transformation of the learning system be enacted. The category of interdependent creativity that we suggest as a tool to apprehend these dynamics is well represented throughout our analysis, in the active exchanges between all the actors (human and non-human), within management constraints. The creativity we have explored in this paper is a social and cognitive act that takes place during the seeking of solutions, building of artefacts, and the knowledge generation at the core of the professionality dynamics. This act is not necessarily new in and of itself - as in a classic interpretation of creativity - but new in a situated Virtual World. It is an adaptive response: a sociotechnical network.

As suggested by Law and Liang (2019), this sociotechnical perspective allows us to examine the nurturing conditions for teachers' and pupils' creativity and contribute to a deep understanding of the historical sustainability and system-level scalability of this social change brought about by technological innovation. We consider this reflection particularly useful in light of COVID-19, which the educational institution in France and elsewhere has suffered since the spring of 2020. The individual (pupil, teacher and researcher) has been conditioned and forced into social and physical isolation. Therefore, the creative process has had to find other spaces for expression, no longer supported by the usual social, emotional and physical infrastructure. Covid-19 shows the necessity to activate interdependent creativity 
even in the new temporary conditions. The activity carried out in the VW reality has allowed pupils, teachers, researchers, and stakeholders to maintain contact with each other and feel part of a network. Therefore, the creative process accumulated over time, has been a resource in the management in the conditions of COVID-19, despite the isolation and disintegration of the sociotechnical network. Heterogeneity proves to be a supporting factor in the creative process. It allows a transformation, adaptation, and more effective management of essential changes and those that Covid-19 may have proposed. Teachers' professionality found a space for expression in the $\mathrm{WW}$ in a possible transfer of acquired skills.

The collaboration in the network and the tensions between the actors have been tested in the stressful situation of Covid-19, however showing the added value of the learning path made over the years. After the school's reopening, the return to school resumed with immediate implementation of the pedagogical scenarios, as wanted by the teachers and the pupils.

Future publications will need to take into consideration the broader territorial transformation at stake. Indeed, this transformation process will need to be further analysed to shed light on workings at stake on a larger scale in and around the use of Virtual Worlds in schools. Future research will also need to address how introducing this new digital technology puts a novel non-linguistic bodily and visual quality at the centre of the users' experience, opening a multimodal learning journey. This research trend has implications for didactics, pupil-teacher interaction, and the pupils' corporal and cognitive behaviour in the classroom and online.

\section{References}

Akrich, M., Callon, M., Latour, B. and Monaghan, A. (2002), "The key to success in innovation part I: the art of interessement", International journal of innovation management, Vol. 6 No 2, pp. 187-206.

Amabile, T. M. (1996), Creativity in Context, Westview Press, Boulder.

Bartels, G. and Bencherki, N. (2013), "Actor-Network-Theory and Creativity Research", In: Carayannis E. G. (Ed.s.), Encyclopedia of Creativity, Invention, Innovation and Entrepreneurship, Springer, New York, NY, https://doi.org/10.1007/978-1-4614-3858-8.

Callon, M. and Law, J. (1997), "After the Individual in Society: Lessons on Collectivity from Science, Technology and Society”, The Canadian Journal of Sociology / Cahiers Canadiens de Sociologie, Vol. 22 No. 2, pp. 165-182, https://doi.org/10.2307/3341747.

Chatsuwan, P., Koraneekij, P. and Na-Songkhla, J. (2020), "Development of Instructional Model Using ProblemBased Learning with Lateral Thinking on Isometric Virtual World to Enhance Creative Problem-Solving of Undergraduate Students", Journal of Information Science, Vol. 38 No.1, pp. 1-19, https://doi.org/10.14456/jiskku.2020.1.

Chen J., Kent, S. (2020), "Task engagement, learner motivation and avatar identities of struggling English language learners in the 3D", Virtual World, System", Vol. 88, https://doi.org/10.1016/j.system.2019.102168.

Craig, T. Y. and Kelly, J. R. (1999), Group cohesiveness and creative performance. Group dynamics: Theory, research, and practice, Vol. 3 No. 4, pp. 243-256.

Dawley, L. and Dede, C. (2014), "Situated learning in Virtual Worlds and immersive simulations in Spector", In: Merrill, M.D. Elen, J. and Bishop M. D. (Ed.s), Handbook of research on educational communications and technology, Springer, New York, pp. 723-734.

Daskolia, M., Kolovou, A. and Kynigos, C. (2015), "Social Creativity in the Design of Digital Resources Interweaving Math with Environmental Education - The Case Study of the Climate Change C-Book",

In: Proceedings of the 8th International Conference on Computer Supported Education (CSEDU 2016), Vol. 1, available from https://www.scitepress.org/Papers/2016/58101/58101.pdf, [accessed 16 january 2020], pp. 134-143.

Evans, L. (2008), "Professionalism, Professionality and the Development of Education Professionals", British Journal of Educational Studies, Vol. 56 No.1, pp. 20-38.

Essonnier, N. K. (2018), "Étude de la conception collaborative de ressources numériques mathématiques au sein d'une communauté d'intérêt", Doctoral dissertation, Université de Lyon, NNT: 2018LYSE1068f, available from https://tel.archives-ouvertes.fr/tel-01868226 [accessed 6 February 2020].

Ferguson, R. (2011), "Meaningful learning and creativity in Virtual Worlds", Thinking Skills and Creativity, Vol. 6, No. 3, pp. 169-78, https://doi.org/10.1016/i.tsc.2011.07.001.

Festinger, L. (1950), “Informal social communication”. Psychological review, Vol. 57 No.5, pp. 271.

Gadille, M. and Impedovo, M. A. (2019), "School Goes Online With Avatars: Extended Learning in a Secondary School”, In: Lund K., Niccolai G. P., Lavoué E., Hmelo-Silver C., Gweon G. and Baker M., A Wide Lens: Combining Embodied, Enactive, Extended, and Embedded Learning in Collaborative Settings, 13th 
International Conference on Computer Supported Collaborative Learning. Conference Proceedings Vol. 2, International Society of the Learning Sciences (ISCL), ISBN: 978-1-7324672-4-8, pp. 549-552.

Gadille, M. and Impedovo, M. A. (2020), "The Embodiment Dimension while Learning and Teaching in a Virtual World", Journal of Systemics, Cybernetics and Informatics: JSCI, Vol. 18 No 3, pp.1-8, http://www.iiisci.org/journal/sci/FullText.asp?var=\&id=EB736RU20.

Girvan, C. (2018), "What is a Virtual World? Definition and classification", Educational Tech Research and Dev, Vol 66 No 5, pp. 1087-1100, https://doi.org/10.1007/s11423-018-9577-y.

Glăveanu, V. P. (2012), "Creativity and Culture: Towards a Cultural Psychology of Creativity in Folk Art", thesis submitted to the Institute of Social Psychology of the London School of Economics, London, May, available from http://etheses.Ise.ac.uk/415/1/Glaveanu Creativity\%20and\%20culture.pdf [accessed 12 February 2020].

Gotlieb, R., Hyde, E., Immordino-Yang, M. and Kaufman, S. (2019), "Imagination Is the Seed of Creativity", In: Kaufman J. and Sternberg R. (Ed.s.), The Cambridge Handbook of Creativity, Cambridge University Press, Cambridge, https://doi.org/10.1017/9781316979839.036 pp. 709-731

Grassin, J.-F. (2015), "Affordances d'un réseau social pour une formation en Français Langue Etrangère: pratiques discursives, modes de participation et présence sociale en ligne", thèse de doctorat, Université Lumière Lyon 2, Lyon, available from https://hal.archives-ouvertes.fr/tel-01249215 [accessed 6 February 2020).

Gregory, S. and Wood, D. (2018), Authentic Virtual World Education. Facilitating Cultural Engagement and Creativity, Springer, Singapore.

Guegan, J., Buisine, S., Mantelet, F., Maranzana, N. and Segonds, F. (2016), "Avatar-mediated creativity: When embodying inventors makes engineers more creative", Computers in Human Behavior, Vol. 61, pp. 165175, https://doi.org/10.1016/i.chb.2016.03.024.

Hammick, J. K. and Lee, M. J. (2014), "Do shy people feel less communication apprehension online? The effects of virtual reality on the relationship between personality characteristics and communication outcomes", Computers in Human Behavior, Vol. 33, pp. 302-310, https://doi.org/10.1016/i.chb.2013.01.046.

Impedovo, M. A. and Gadille M. (2021), "Embodiment in knots of sense-making between learning physical and virtual configurations", E-Learning and Digital Media, Vol. 18 No 2, 145-162. https://doi.org/10.1177/2042753020978484.

Jarmon, L., Traphagan, T., Mayrath, M. and Trivedi, A. (2009), Virtual world teaching, experiential learning, and assessment: An interdisciplinary communication course in Second Life. Comput. Educ. Vol. 53 No. 1, pp. 169-182, http://dx.doi.org/10.1016/j.compedu.2009.01.010.

Jonassen, D. H., Howland, J. L., Moore, J. L. and Marra, R. M. (2003), Learning to solve problems with technology: A constructivist perspective, Merrill Prentice Hall, Upper Saddle River, New Jersey.

Latour, B. (1999a), "On recalling ANT", The sociological review, Vol. 47 (1_suppl), pp. 15-25.

Latour, B. (1999b), The Pandora's Hope. Essay on the Reality of Sciences Studies, Harvard University Press, Cambridge Mass.

Law, N. and Liang, L. (2019), "Sociotechnical co-evolution of an e-Learning innovation network", Br J Educ Technol, Vol. 50 No 3, pp. 1340-1353, https://berajournals.onlinelibrary. wiley.com/doi/pdf/10.1111/bjet.12768.

Mainemelis, C. and Ronson, S. (2006), "Ideas are born in fields of play: Towards a theory of play and creativity in organizational settings", Research in Organizational Behavior, Vol. 27, pp. 81-131.

McIntyre, A. (2008), Participatory Action Research, Qualitative Research Methods Series 52, Sage, Los Angeles.

Mishra, P., Henriksen, D. and Mehta, R. (2019), "Creativity, Digitality, and Teacher Professional Development: Unifying Theory, Research, and Practice", In: Management Association, I. (Ed.), TPACK: Breakthroughs in Research and Practice, IGI Global, http://doi:10.4018/978-1-5225-7918-2.ch006, pp. 123-154.

Tsvetkova, M., Yasseri, T., Meyer, E., Pickering J. B., Engen V., Walland, P., Lüders, M., Følstad, A. and Bravos G. (2017), "Understanding Human-Machine Networks: A Cross-Disciplinary Survey", ACM Comput. Surv. Vol. 50 No. 1 , Article 12, 35 p., https://doi.org/10.1145/3039868.

Vygotsky, L. S. (2004), "Imagination and creativity in childhood", Journal of Russian \& East European Psychology, Vol. 42 No. 1, pp. 7-97. 